\title{
New Record of Sebastes nudus and Redescription of Sebastes pachycephalus (Pisces: Scorpaenidae) from Korea
}

\author{
Hyo Jae Yu, Jin-Koo Kim* \\ Department of Marine Biology, Pukyong National University, Busan, 608-737, Korea
}

\begin{abstract}
Using the criteria of previous study, we analyzed the morphological characters of 66 specimens of the Sebastes pachycephalus complex collected from Korea between 2008 and 2013. As a result, the 37 specimens were identified as Sebastes nudus, and the remaining specimens as Sebastes pachycephalus. Sebastes nudus is characterized by the absence of scales below the base of the dorsal fin spines; the absence of dark spots on the dorsal, anal, and caudal fins; and the presence of distinct yellow or brownish-red markings on the dorsum (when fresh). The most similar species $S$. pachycephalus differs from $S$. nudus in having minute scales below the base of the dorsal fin spines. We propose the new Korean name "Hwang-jeom-gae-bol-rak" for $S$. nudus, and redescribe S. pachycephalus.
\end{abstract}

Key words: Sebastes nudus, Sebastes pachycephalus, New record, Redescription, Korea

\section{Introduction}

Sebastes pachycephalus Temminck and Schlegel 1843 belonging to the family Scorpaenidae is commonly seen in shallow rocky areas in the northwestern Pacific including Korea and Japan (Nakabo, 2002; Nelson, 2006). Because of the great variations in coloration, its taxonomy has been confused (Jordan and Starks, 1904; Matsubara, 1943; Amaoka, 1984; Nakabo, 2002). Matsubara (1943) first divided S. pachycephalus into four subspecies (Sebastes pachycephalus pachycephalus, S. p. nigricans, S. p. nudus, and S. p. chalcogrammus), and then Nakabo (2002) further reassigned them into two groups (group S. p. pachycephalus and S. p. nigricans, group S. p. nu$d u s$ and $S$. p. chalcogrammus). Recently, using morphological and molecular methods, Kai et al. (2011) and Kai and Nakabo (2013) demonstrated that only S. pachycephalus and S. nudus are distinct species. In Korea, $S$. pachycephalus was first reported as Sebastichthys pachycephalus by Jordan and Metz (1913). Later, Chyung (1961) redescribed the specimens as S. pachycephalus, subsequently many Korean Ichthyologists used the scientific name (Chyung, 1977; Kim et al., 2005). In the present study, we detected the presence of two distinct species within the Korean Sebastes pachycephalus complex. Accordingly, we describe $S$. nudus as the first record in Korea and redescribe $S$. pachycephalus based on specimens.

\section{Materials and Methods}

A total of 66 specimens of $S$. pachycephalus complex were collected from the East Sea, the Korean Strait and water off Jeju Island, Korea between July 2008 and August 2013 (Fig. 1). Based on morphological comparisons, 37 specimens were identified as $S$. nudus and 29 specimens as $S$. pachycephalus. Counts and measurements were conducted according to the methods of Hubbs and Lagler (2004), with digital vernier caliper to the nearest $0.1 \mathrm{~mm}$. Significant differences in the measurements were tested between $S$. nudus and $S$. pachycepha-
http://dx.doi.org/10.5657/FAS.2014.0129

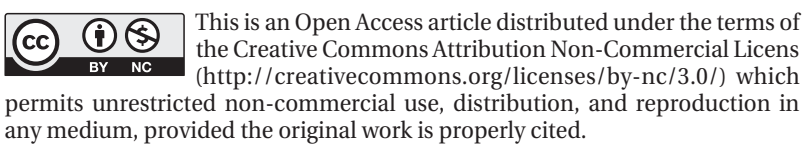

Received 28 October 2013; Revised 28 January 2013

Accepted 29 January 2013

*Corresponding Author

E-mail: taengko@hanmail.net 


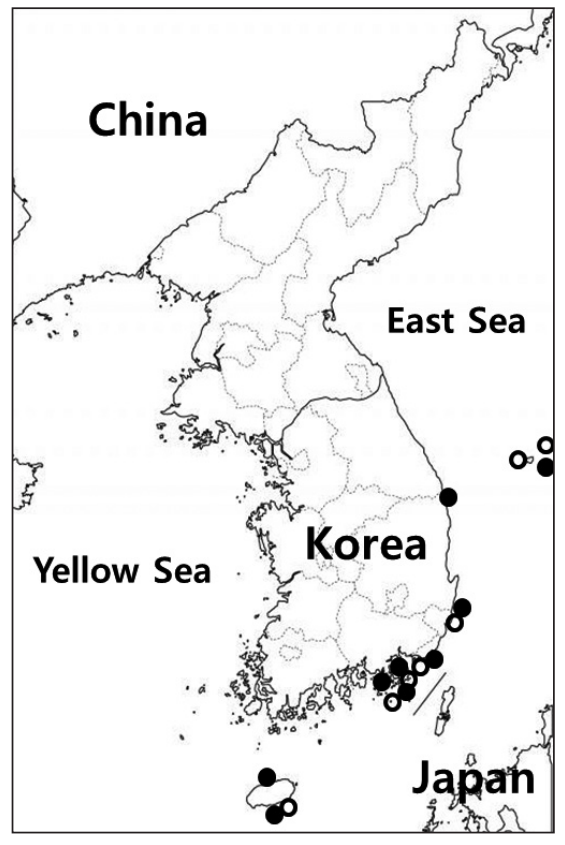

Fig. 1 Sampling sites of Sebastes nudus ( $(\bullet)$ and Sebastes pachycephalus (0).

lus with Student's $t$ test (version 18; SPSS Inc., Chicago, IL, USA). The specimens of $S$. nudus are deposited at the Department of Marine Biology, Pukyoung National University (PKU) and in the National Institute of Biological Resources (NIBR), Korea.

\section{Results and Discussion}

\section{Sebastes nudus Matsubara 1943}

(new Korean name: Hwang-jeom-gae-bol-rak) (Table 1, Fig. 2)

Sebastes (Murasoius) pachycephalus, form. nudus: Matsubara 1943: 239 (type locality: Hakodate, Hokkaido, Japan and Busan, Korea).
Sebastes (Murasoius) pachycephalus, form. chalcogrammus: Matsubara 1943: 244 (type locality: Shimonoseki, Japan).

Sebastes pachycephalus nudus: Matsubara, 1955: 1077; Nakabo, 2002: 595.

Sebastes pachycephalus chalcogrammus: Matsubara, 1955: 1077; Nakabo, 2002: 595.

Sebastes pachycephalus (not of Temminck \& Schlegel): Kim et al., 2005: 222.

Sebastes pachycephalus complex "species Nu-C": Kai et al., 2011: 333 .

Sebastes nudus: Kai and Nakabo, 2013: 551.

\section{Materials examined}

Thirty seven specimens, $100.5-179.6 \mathrm{~mm}$ in standard length (SL); NIBR P22474, 1 specimen, 170.4 mm SL, Tongyeong, Gyeongsangnam-do, Korea, 18 Jun 2013; PKU 208, 210-216, 8 specimens, 100.5-119.3 mm SL, Tongyeong, Gyeongsangnam-do, Korea, 22 Jul 2008; PKU 1585, 1 specimen, 128.4 mm SL, Udupo, Goseong, Gyeongsangnam-do, Korea, 25 Feb 2009; PKU 2006, 1 specimen, 115.7 mm SL, Geojedo, Gyeongsangnam-do, Korea, 29 May 2009; PKU 2051, 1 specimen, 121.04 mm SL, Saeng-do, Busan, Korea, 31 May 2009; PKU 2090-2091, 2135, 2137-2138, 5 specimens, 121.6136.6mm SL, Geoje-do, Gyeongsangnam-do, Korea, 11 Jun 2009; PKU 3404, 1 specimen, 153.2 mm SL, Seogwipo-si, Jeju-do, Korea, 4 Feb 2010; PKU 4045, 4047, 2 specimens, 133.1-163.1 mm SL, Uljin, Gyeongsangbuk-do, Korea, 22 Jun 2010; PKU 6174, 6192, 2 specimens, 153.4-179.6 mm SL, Dok-do, Gyeongsangbuk-do, Korea, 28 Aug 2011; PKU 8759-8761, 3 specimens, 133.6-162.3 mm SL, Geoje-do, Gyeongsangnam-do, Korea, 12 May 2013; PKU 9443-9444, 2 specimens, 132.3-141.3 mm SL, Jeongja-dong, Ulsan, Korea, 19 Jul 2013; PKU 9445, 1 specimen, 163.2 mm SL, Jeju-si, Jeju-do, Korea, 15 Jun 2013; PKU 9456, 1 specimen, 149.7 mm SL, Tongyeong, Gyeongsangnam-do, Korea, 18 Jun 2013; PKU 9458-9461, 4 specimens, 117.1-142.6 mm SL, Geoje-do, Gyeongsangnam-do, Korea, 25 May 2013; PKU 9462, 1 specimen, 120.3 mm SL, Tongyeong, Gyeongsangnam-do, Korea,

Table 1. Comparison of counts of Sebastes nudus among present study and others

\begin{tabular}{|c|c|c|c|c|}
\hline & \multirow[b]{2}{*}{ Present study } & \multicolumn{2}{|c|}{ Matsubara (1943) } & \multirow{2}{*}{$\begin{array}{c}\text { Kai and Nakabo } \\
\text { (2013) }\end{array}$} \\
\hline & & $\begin{array}{l}\text { Holotype of } S . \text { nudus } \\
\text { FAKU } 352\end{array}$ & $\begin{array}{c}\text { Holotype of } S \text {. chalcogrammus } \\
\text { FAKU } 6317\end{array}$ & \\
\hline No. of specimens & 37 & - & - & 86 \\
\hline Standard length $(\mathrm{mm})$ & $100.5-179.6(131.8)$ & 198.5 & 261.8 & $23.2-212.8(143.6)$ \\
\hline Dorsal fin rays & X III, 11-14 & X III, 12 & X III, 13 & X III, 10-13 \\
\hline Anal fin rays & III, 6 & III, 5 & III, 6 & III, 5-7 \\
\hline Pectoral fin ray (right) & $16-18$ & 17 & 17 & $16-18$ \\
\hline Pectoral fin ray (left) & $16-18$ & 17 & 18 & $16-18$ \\
\hline Pored lateral-line scales & $29-33$ & 32 & 32 & $29-33$ \\
\hline
\end{tabular}



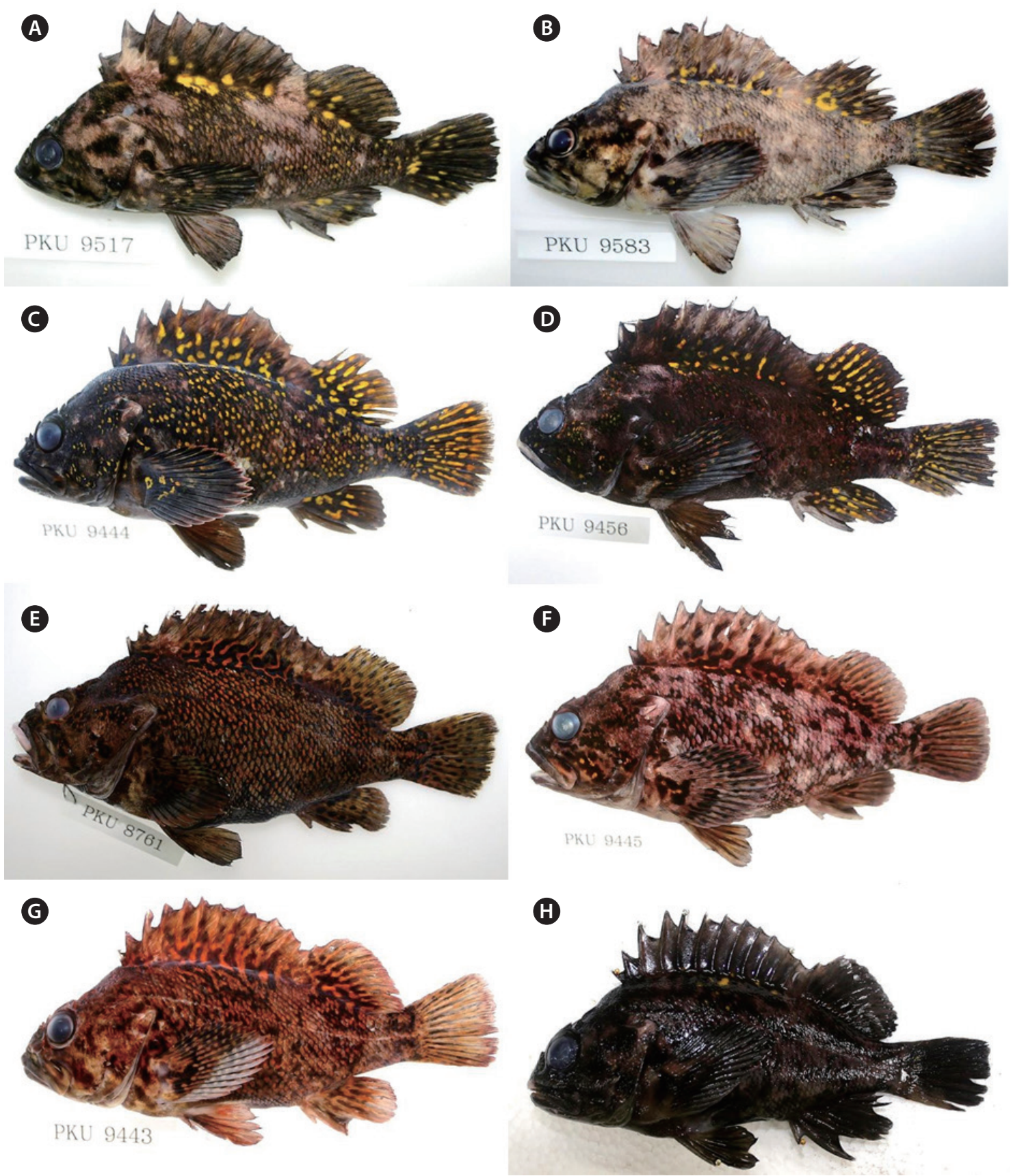

Fig. 2. Sebastes nudus when fresh. (A) PKU 9517, $126.51 \mathrm{~mm}$ standard length (SL), Saeng-do, Busan, Korea. (B) PKU 9583, $125.38 \mathrm{~mm}$ SL, Ulsan, Korea. (C) PKU 9444, 141.26 mm SL, Jeongja-dong, Ulsan, Korea. (D) PKU 9456, 149.66 mm SL, Tongyeong, Gyeongsangnam-do, Korea. (E) PKU 8761, 154.97 mm SL, Geoje-do, Gyeongsangnam-do, Korea. (F) PKU 9445, 163.17 mm SL, Jeju-do, Korea. (G) PKU 9443, 132.29 mm SL. Jeongja-dong, Ulsan, Korea. (H) PKU 9462, $120.31 \mathrm{~mm}$ SL, Tongyeong, Gyeongsangnam-do, Korea.

31 May 2013; PKU 9517, 1 specimen, 126.5 mm SL, Saengdo, Busan, Korea, 24 Jul 2013; PKU 9582-9583, 2 specimens, 116.2-125.4 mm SL, Ulsan, Korea, 5 Aug 2013.

\section{Description}

D. X III, 11-14; A. III, 6; P. 16-18; P. I, 5; LLp. 29-33.
Counts and measurements are shown in Tables 1 and 2 .

Body relatively deep, moderately compressed, steeply inclined from snout to origin of the dorsal fin (Fig. 2). Mouth large and slightly oblique upward. Posterior margin of the maxilla reaching to the posterior margin of the orbit. Head large and completely covered with ctenoid scales, except for 

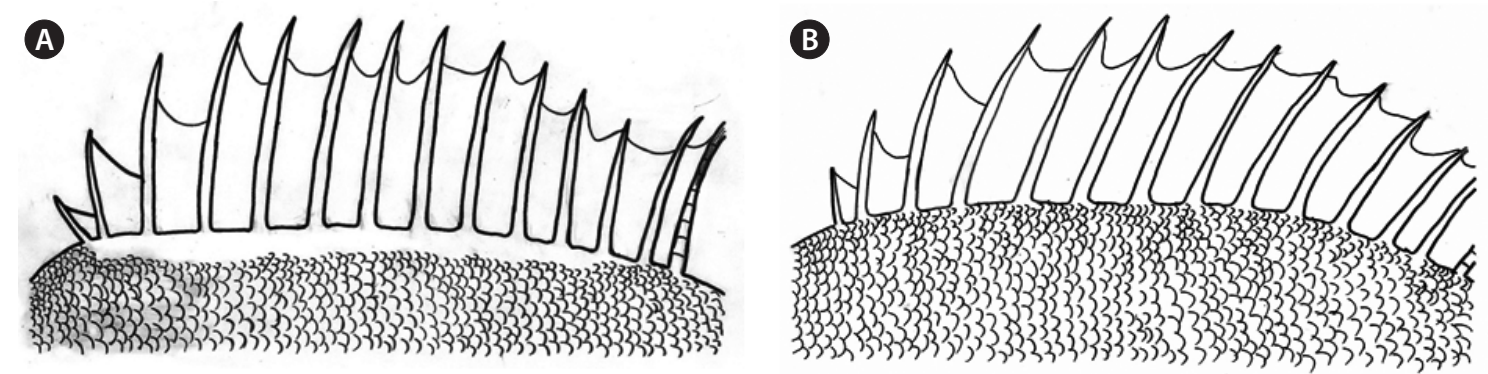

Fig. 3. Sebastes nudus (A) and Sebastes pachycephalus (B), showing the squamation pattern below the base of the dorsal fin spines.

the tip of the snout, maxillary, lacrimal, lower jaw, interopercle, and branchiostegal membranes. Eye relatively large and round. Interorbital region concave and covered with scales. A single pair of nostril presents in front of eye. Strong spines well developed in the head: nasal spine simple, sharp, directed dorsally; preocular spine robust, well developed; supraocular spine robust, well developed, tip of spine reaching or extending beyond the posterior margin of the orbit; postocular spines simple, directed dorsoposteriorly; parietal spine well developed; suborbital without spine or ridge; lacrimal with round lobe anteriorly and one spine posteriorly, the spine sharp, directed dorsally; preopercle with five spines, first and second spines large, well developed, directed posteriorly, fourth and fifth spines small, blunt, directed ventroposteriorly; opercle with two sharp spines, directed posteriorly, upper spine somewhat larger than lower spine. Body covered with ctenoid scales, except for the pectoral fin base, prepelvic region and ventral abdominal region. Pectoral fin base, prepelvic region and ventral abdominal region covered with cycloid scales, ventral abdominal usually surface with narrow naked area anteriorly. No minute scales below the base of the entire spinous portion of the dorsal fin, but sometimes with minute scales below the first to fifth spines or variously to posteriormost spine (Fig. 3). First dorsal spine short, fifth spine longest, last spine longer than the penultimate spine. All dorsal soft rays branched, entire margin rounded. Caudal fin slightly convex but close to truncate. Pectoral fin rounded, not reaching posteriorly to the anus. Second anal spine robust, longest.

\section{Coloration}

Sebastes nudus shows much variation in its coloration, including in the color, size, number, and distribution of the markings on the body, head, and fins (Fig. 2A-2H). When fresh, the body and head are generally brown or dark brown, sometimes with a light brown (Fig. 2A, 2B, and 2F) or reddish pattern on the body (Fig. 2F and 2G). The head has three dark brown irregular bands radiating from the eye. The dorsal, caudal, anal, and pectoral fins generally lack dark brown spots, sometimes present but then indistinct. Dorsum part of the body and dorsal, caudal, and anal fins have irregular yellow or brownish-red markings (Fig. $2 \mathrm{~A}-2 \mathrm{G}$ ), but sometimes small and indistinct (Fig. 2H). Yellow or brownish-red markings occasionally occur on the head and pectoral fin base (Fig. 2C, 2D, and 2F). After fixation in formalin, the head and body are dark overall. Yellow and brownish-red markings when fresh, appearing as pale or white markings when preserved.

\section{Distribution}

East Sea, Korean Strait, and Jeju Island in Korea (present study), Japan (from southern Hokkaido southward along the Pacific coast of Japan to Kanagawa, the east coast of Japan to northern Kyushu Island, Seto Inland Sea) (Kai and Nakabo, 2013), and China (Bohai and Yellow Sea) (Kai and Nakabo, 2013).

\section{Remarks}

The present specimens were identified as $S$. nudus, based on the following characters: lack of scales below the base of the dorsal fin spines, and yellow or brownish-red markings on the dorsum (Kai and Nakabo, 2013). This species is very similar morphologically to $S$. pachycephalus, but they are easily distinguishable by the minute scales below the base of the dorsal fin spines (present in $S$. pachycephalus vs. absent in $S$. $n u d u s$ ), the dark spots on the dorsal, anal, and caudal fins (distinct in S. pachycephalus vs. faint in S. nudus), and the yellow or brownish-red markings on the dorsum (absent in S. pachycephalus vs. present in $S$. nudus) (Kai and Nakabo, 2013). S. nudus also differs from $S$. pachycephalus in the size of each fin (those of S. nudus are larger than those of S. pachycephalus) and the number of pectoral fin rays (17-19 in S. pachycephalus $[$ mode $=18]$ vs. $16-18$ in $S$. nudus $[$ mode $=17])($ Tables 2, 3). Our results correspond well with the previous study (Kai and Nakabo, 2013). Therefore, we propose a new Korean name "Hwang-jeom-gae-bol-rak" for S. nudus.

\section{Sebastes pachycephalus Temminck and Schlegel 1843}

(Korean name: gae-bol-rak) (Table 4, Fig. 4)

Sebastes pachycephalus Temminck \& Schlegel 1843: 47 (type locality: Nagasaki, Japan).

Sebastes (Murasoius) pachycephalus, form. pachycepha- 
Table 2. Comparison of measurements between Sebastes nudus and S. pachycephalus

\begin{tabular}{|c|c|c|c|c|}
\hline & \multicolumn{2}{|c|}{ S. nudus } & \multicolumn{2}{|c|}{ S. pachycephalus } \\
\hline & Present study & Kai and Nakabo (2013) & Present study & Kai and Nakabo (2013) \\
\hline No. of specimens & 37 & 86 & 29 & 101 \\
\hline Standard length (mm) & $100.5-179.6(131.8)$ & $23.2-212.8(143.6)$ & $100.0-186.1(143.2)$ & $24.9-318.0(122.2)$ \\
\hline \multicolumn{5}{|l|}{ In \% of standard length } \\
\hline Head length & $37.3-43.8(40.1)$ & $38.3-44.2(40.9)$ & $37.3-43.5(39.6)$ & $31.5-44.7(39.4)$ \\
\hline Snout length & $8.9-12.8(11.0)$ & $9.0-12.4(10.2)$ & $8.8-12.1(10.7)$ & $8.5-11.9(10.2)$ \\
\hline Orbit dismeter & $7.8-11.2(9.4)$ & $8.2-12.3(9.9)$ & $7.8-12.3(9.0)$ & $7.8-12.8(9.8)$ \\
\hline Interorbital width & $5.4-7.9(6.5)$ & $4.3-9.0(5.7)$ & $4.8-7.3(6.0)$ & $3.8-8.1(5.2)$ \\
\hline Body depth & $33.2-42.6(37.9)$ & $33.4-43.8(38.3)$ & $32.8-41.5(36.7)$ & 28.6-44.4 (36.8) \\
\hline Body width & $17.5-25.4(21.5)$ & $14.5-37.4(21.4)$ & $18.4-24.9(21.4)$ & $15.2-32.3(20.5)$ \\
\hline Caudal peduncle depth & $10.7-25.4(21.5)$ & $10.4-12.9(11.8)$ & $10.9-12.4(11.7)$ & $8.3-14.1(11.3)$ \\
\hline Upper jaw length & $15.8-20.6(19.1)$ & $16.7-21.7(19.5)$ & $16.8-22.1(18.7)$ & $15.3-22.5(19.2)$ \\
\hline Predorsal-fin length & $32.6-37.4(35.2)$ & $32.7-38.5(35.4)$ & $29.2-64.2(35.8)$ & $28.6-39.2(35.1)$ \\
\hline Preanal-fin length & $19.2-77.6(70.0)$ & $41.7-80.5(72.2)$ & $66.6-76.6(71.2)$ & $55.7-80.9(71.6)$ \\
\hline Pectoral-fin length & $25.3-32.4(29.6)^{* *}$ & $25.5-41.7(30.4)$ & $23.5-31.3(27.6)^{* *}$ & $22.9-34.8(28.9)$ \\
\hline Pelvic-fin length & $20.7-26.1(23.5)^{* *}$ & $20.0-27.0(23.4)$ & $19.3-24.5(21.8)^{* *}$ & $19.8-28.1(23.2)$ \\
\hline Pelvic-fin spine length & $10.3-17.2(15.2)^{* *}$ & $11.9-17.9(15.1)$ & $12.0-15.9(13.8)^{* *}$ & $10.3-17.3(14.3)$ \\
\hline 1st dorsal-fin spine length & $4.3-7.4(5.8)$ & $3.5-8.9(6.6)$ & $4.1-8.5(5.4)$ & $3.1-7.2(5.5)$ \\
\hline 2nd dorsal-fin spine length & $6.4-13.3(10.3)^{* *}$ & 7.4-13.4 (10.8) & $7.0-11.4(8.8)^{* *}$ & $6.3-12.2(9.1)$ \\
\hline 3rd dorsal-fin spine length & $9.6-18.2(14.3)^{* *}$ & $11.2-17.6(15.1)$ & $3.6-15.0(11.7)^{* * *}$ & $9.8-15.7(12.7)$ \\
\hline 4th dorsal-fin spine length & $12.0-18.9(16.2)^{* * *}$ & $13.7-19.9(16.7)$ & $10.3-17.0(13.7)^{* *}$ & $11.2-17.3(14.4)$ \\
\hline 5th dorsal-fin spine length & $12.1-19.3(16.7)^{* *}$ & $13.1-20.1(16.9)$ & $11.0-17.9(14.3)^{* *}$ & $11.3-17.9(14.7)$ \\
\hline 12th dorsal-fin spine length & $8.5-13.3(10.6)^{* *}$ & $8.0-13.6(11.0)$ & $6.8-12.0(9.0)^{* *}$ & 7.6-12.0 (9.7) \\
\hline 13th dorsal-fin spine length & $9.7-14.2(11.8)^{* *}$ & 9.4-14.1 (11.9) & $8.0-12.9(10.7)^{* *}$ & $8.6-14.3(11.4)$ \\
\hline Longest dorasl-fin ray length & $13.4-20.0(17.0)^{* *}$ & $14.8-21.0(18.3)$ & $10.3-18.2(15.4)^{* *}$ & $13.6-22.3(17.6)$ \\
\hline 1st anal-fin spine length & $6.4-10.8(8.7)^{*}$ & $6.3-10.7(8.7)$ & $5.9-16.1(7.8)^{*}$ & $4.9-9.7(8.0)$ \\
\hline 2nd anal-fin spine length & $13.2-21.7(18.4)^{* *}$ & $10.4-20.3(17.2)$ & $12.2-20.6(16.1)^{* *}$ & $11.9-21.5(16.9)$ \\
\hline 3rd anal-fin spine length & $13.0-19.1(16.6)^{* * *}$ & 8.8-18.7 (15.3) & $12.8-18.4(15.0)^{* *}$ & $10.8-18.9(15.1)$ \\
\hline Distance between pelvic and anal-fin & $22.8-39.8(32.3)$ & $25.6-40.1(33.2)$ & 24.9-341.2 (32.9) & $24.7-47.5(33.1)$ \\
\hline
\end{tabular}

Parentheses indicate means.

Significant differences between Sebastes nudus and Sebastes pachycephalus in the present study ( $\left.P<0.05,{ }^{* *} P<0.01\right)$.

Table 3. Comparison of the frequency of number of pectoral fin rays between $S$. nudus and S. pachycephalus

\begin{tabular}{|c|c|c|c|c|c|c|c|c|c|c|}
\hline & \multicolumn{5}{|c|}{ Pectoral-fin rays (right side) } & \multicolumn{5}{|c|}{ Pectoral-fin rays (left side) } \\
\hline & 16 & 17 & 18 & 19 & 20 & 16 & 17 & 18 & 19 & 20 \\
\hline \multicolumn{11}{|l|}{ S. nudus } \\
\hline Present study & 1 & 29 & 7 & - & - & 2 & 29 & 6 & - & - \\
\hline Kai and Nakabo (2013) & 6 & 70 & 9 & - & - & 9 & 67 & 12 & - & - \\
\hline \multicolumn{11}{|l|}{ S. pachycephalus } \\
\hline Present study & 1 & 1 & 20 & 7 & - & - & 1 & 24 & 4 & - \\
\hline Kai and Nakabo (2013) & - & 23 & 60 & 18 & 2 & 1 & 18 & 64 & 17 & 2 \\
\hline
\end{tabular}


lus: Matsubara 1943: 239 (Chiba, Kanagawa, Aichi, Wakayama, and Kobe, Japan).

Sebastes (Murasoius) pachycephalus, form. nigricans: Matsubara 1943: 242 (Shimonoseki and Nagasaki, Japan).

Sebastes pachycephalus pachycephalus: Matsubara, 1955: 1077 (Chiba southward to Kyushu, Japan, Busan, Korea, and China); Chyung, 1977: 500; Nakabo, 2002: 595.

Sebastes pachycephalus nigricans: Matsubara, 1955: 1077; Nakabo, 2002: 595.

Sebastes pachycephalus complex "Species P-Ni": Kai et al., 2011: 333 .

Sebastes pachycephalus: Kai and Nakabo, 2013: 542.

\section{Materials examined}

Twenty seven specimens, 100.0-186.1 $\mathrm{mm}$ in standard length (SL); PKU 200-206, 5 specimens, 100.0-173.8 mm SL, Tongyeong, Gyeongsangnam-do, Korea, 22 Jul 2008; PKU 4046, 4048, 2 specimens, 114.5-186.1 mm SL, Uljin, Gyeongsangbuk-do, Korea, 22 Jun 2010; PKU 5259, 5265, 2 specimens, 142.4-157.6 mm SL, Ulleung, Gyeongsangbukdo, Korea, 27 Mar 2011; PKU 6168, 6170, 6172-6173, 61786180, 6188, 6190-6191, 6195, 6401, 6403, 13 specimens, 118.0-167.8 mm SL, Dok-do, Gyeongsangbuk-do, Korea, 27 Aug 2011; PKU 7094, 1 specimen, $170.1 \mathrm{~mm}$ SL, Dok-do, Gyeongsangbuk-do, Korea, 6 Sep 2012; PKU 8756-8757, 2 specimens, 138.9-145.6 mm SL, Geoje-do, Gyeongsangnamdo, Korea, 12 May 2013; PKU 9442, 1 specimen, $129.5 \mathrm{~mm}$ SL, Jeongja-dong, Ulsan, Korea, 19 Jul 2013; PKU 9638, 1 specimen, 153.8 mm SL, Dadepo, Bussan, Korea, 2 Jun 2013; PKU 9639-9640, 2 specimens, 137.9-158.8 mm SL, Seogwipo-si, Jeju-do, Korea, 13 Jun 2013.

\section{Description}

D. X III, 11-14; A. III, 6; P . 17-19; P . I, 5; LLp. 29-33. Counts and measurements are shown in Tables 2 and 4.

Body relatively deep, moderately compressed, steeply inclined from snout to origin of the dorsal fin (Fig. 4). Mouth large and slightly oblique upward. Posterior margin of the maxilla reaching to the posterior margin of the orbit. Head large and completely covered with ctenoid scales, except for the tip of the snout, maxillary, lacrimal, lower jaw, interopercle, and branchiostegal membranes. Eye relatively large and round. Interorbital region concave and covered with scales. A single pair of nostril presents in front of eye. Strong spines well developed in the head: nasal spine simple, sharp, directed dorsally; preocular spine robust, well developed; supraocular spine robust, well developed, tip of spine reaching or extending beyond the posterior margin of the orbit; postocular spines simple, directed dorsoposteriorly; parietal spine well developed; suborbital without spine or ridge; lacrimal with round lobe anteriorly and one spine posteriorly, the spine sharp, directed dorsally; preopercle with five spines, first and second spines large, well developed, directed posteriorly, fourth and fifth spines small, blunt, directed ventroposteriorly; opercle with two sharp spines, directed posteriorly, upper spine somewhat larger than lower spine. Body covered with ctenoid scales, except for the pectoral fin base, prepelvic region and ventral abdominal region. Pectoral fin base, prepelvic region and ventral abdominal region covered with cycloid scales, ventral abdominal surface usually with narrow naked area anteriorly. Base of entire spinous portion of the dorsal fin densely covered with minute scales, usually extending onto basal spines and membranes (Fig. 3). First dorsal spine short, fifth spine longest, last spine longer than the penultimate spine. All dorsal soft rays branched, entire margin rounded. Caudal fin slightly convex but close to truncate. Pectoral fin, rounded, not reaching posteriorly to the anus. Second anal spine robust, longest.

\section{Coloration}

Color variation of Sebastes pachycephalus is relatively smaller than S. nudus (Fig. 4A-4D). When fresh, the body and head are generally brown or dark brown, sometimes with light brown band (Fig. 4A and 4C) or light pattern on the body (Fig. 4B and 4D). The head has three dark brown irregular bands radiating from eye. The dorsal, pectoral, anal and caudal fins

Table 4. Comparison of counts of Sebastes pachycephalus among present study and others

\begin{tabular}{|c|c|c|c|c|}
\hline & \multirow[b]{2}{*}{ Present study } & Temminck and Schlegel (1843) & Schmidt (1931) & \multirow{2}{*}{$\begin{array}{c}\text { Kai and Nakabo } \\
\text { (2013) }\end{array}$} \\
\hline & & $\begin{array}{c}\text { Holotype of } S \text {. pachycephalus } \\
\text { FAKU } 352\end{array}$ & $\begin{array}{c}\text { Holotype of } S \text {. nigricans } \\
\text { FAKU } 6317\end{array}$ & \\
\hline No. of specimens & 29 & - & - & 101 \\
\hline Standard length $(\mathrm{mm})$ & $100.0-186.1(143.2)$ & 261.8 & 150.0 & $24.9-318.0(122.2)$ \\
\hline Dorsal-fin rays & X III, 11-14 & X III, 12 & X III, 12 & X III, $10-13$ \\
\hline Anal-fin rays & III, 6 & III, 6 & III, 6 & III, 6 \\
\hline Pectoral-fin ray (right) & $17-19$ & - & 18 & $17-19$ \\
\hline Pectoral-fin ray (left) & $17-19$ & 19 & - & $17-19$ \\
\hline Pored lateral-line scales & $29-33$ & - & 31 & $29-33$ \\
\hline
\end{tabular}



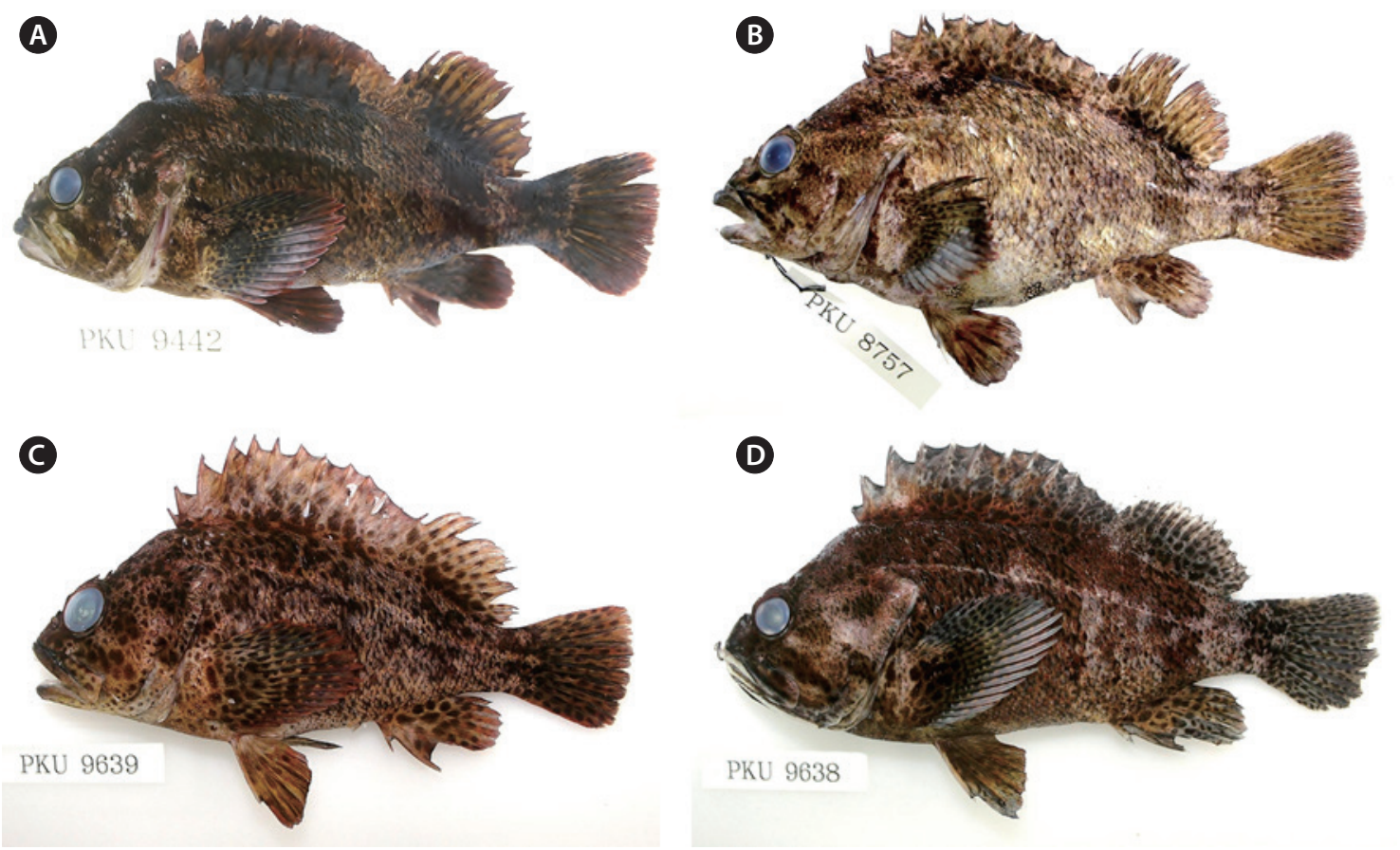

Fig. 4. Sebastes pachycephalus when fresh. (A) PKU 9442, 129.52 mm standard length (SL), Jeongja-dong, Ulsan, Korea. (B) PKU 8757, 145.6 mm SL, Geojedo, Gyeongsangnam-do, Korea. (C) PKU 9639, 137.91 mm SL, Seogwipo-si, Jeju-do, Korea. (D) PKU 9638, 153.76 mm SL, Seogwipo-si, Jeju-do, Korea.

with distinct dark brown spots, sometimes indistinct. Dark brown spots occasionally occur on the head and pectoral fin base (Fig. 4C). After fixation in formalin, the head and body are dark overall. The dorsal, pectoral, anal and caudal fins with dark brown spots.

\section{Distribution}

East Sea, Korean Strait, and Jeju Island in Korea (present study), Japan (from Aomori, northern Honshu Island, southward to Kagoshima Bay, southern Kyushu Island) (Kai and Nakabo, 2013), and China (Yellow and Pohai Sea) (Kai and Nakabo, 2013).

\section{Remarks}

In Korea, S. pachycephalus was first reported as Sebastichthys pachycephalus by Jordan and Metz (1913). Later, Chyung (1961) redescribed the specimens as S. pachycephalus. However, Chyung (1977) presented sketch material using the scientific name of $S$. pachycephalus pachycephalus. His sketch was clearly identified as $S$. pachycephalus based on the following character: minute scales below the base of dorsal fin spines. In recent years, Kim et al. (2005) described S. pachycephalus, in which their photo was clearly identified as $S$. nu$d u s$ because of the yellow markings on the dorsum. In this study, S. pachycephalus in Korea is clearly distinguished from S. nudus according to the criteria of Kai and Nakabo (2013). According to the rule for the priority of naming, therefore, we follow the fish name 'gae-bol-rak' for $S$. pachycephalus.

\section{Acknowledgements}

This research was supported by the project on survey and excavation of Korean indigenous species of the National Institute of Biological Resources (NIBR) under the Ministry of Environment, Korea.

\section{References}

Amaoka K. 1984. Genus Sebastes. In: The Fishes of the Japanese Archipelago. English ed. Masuda H, Amaoka K, Araga C, Uyeno T and Yoshino T, eds. Tokai University Press, Tokyo, JP, pp. 310-313.

Chyung MK. 1961. Illustrated Encyclopedia the Fauna of Korea (2) Fishes. The Ministry of Education, Seoul, KR, pp. 554-555.

Chyung MK. 1977. The Fishes of Korea. Iljisa, Seoul, KR, p. 500.

Hubbs CL and Lagler KF. 2004. Fishes of the Great Lakes Region. Revised ed. Michigan University Press, Ann Arbor, MI, US.

Jordan DS and Metz CW. 1913. A catalog of the fishes known from the waters of Korea. Mem Carnegie Mus 6, 1-65.

Jordan DS and Starks EC. 1904. A review of the scorpaenoid fishes of Japan. Proc U S Natl Mus 27, 91-175. http://dx.doi.org/10.5479/ si.00963801.27-1351.91.

Kai Y and Nakabo T. 2013. Taxonomic review of the Sebastes pachycephalus complex (Scorpaeniformes: Scorpaenidae). Zootaxa 3637, 541-560. 10.11646/zootaxa.3637.5.3.

Kai Y, Nakayama K and Nakabo T. 2011. Genetic and morphological divergence within the Sebastes pachycephalus complex (Scorpae- 
niformes: Scorpaenidae). Ichthyol Res 58, 333-343. http://dx.doi. org/10.1007/s10228-011-0236-0.

Kim IS, Choi Y, Lee CL, Lee YJ, Kim BJ and Kim JH. 2005. Illustrated Book of Korean Fishes. Kyohak Publishing Co., Seoul, KR.

Matsubara K. 1943. Studies on the scorpaenoid fishes of Japan. Anatomy, phylogeny and taxonomy II. Trans Sigenkagaku Kenkyusyo 2, 171-486.

Matsubara K. 1955. Fish Morphology and Hierarchy. Ishizaki-shoten, Tokyo, JP.
Nakabo T. 2002. Scorpaenidae. In: Fishes of Japan with Pictorial Keys to the Species. English ed. Nakabo T, ed. Tokai University Press, Tokyo, JP, pp. 565-595, 1524-1528.

Nelson JS. 2006. Fishes of the World. 4th ed. John Wiley \& Sons, Inc., Hoboken, NJ, US.

Schmidt PJ. 1931. Fishes of Japan, collected in 1901. Trans Pac Committee Acad Sci USSR 2, 1-176.

Temminck CJ and Schlegel H. 1843. Pisces, Parts 2-4. In: de Siebold's Fauna Japonica. Sieold PF, ed, Müller, Amsterdam, NL, pp. 21-72. 